\title{
PENENTUAN MUTU PEKTIN DARI LIMBAH KULIT PISANG DENGAN VARIASI VOLUME PELARUT ASAM SITRAT
}

\author{
V. A. Devianti", L. Sa'diyah, A. R. Amalia \\ Program Studi DIII Farmasi, Akademi Farmasi Surabaya, Surabaya, Jawa Timur, Indonesia \\ *Email: vikaayu@akfarsurabaya.ac.id
}

\begin{abstract}
ABSTRAK
Kebutuhan pektin di Indonesia cenderung meningkat di setiap tahun dan lebih mengandalkan pektin impor untuk memenuhi kebutuhan pektin dalam negeri. Oleh karena itu perlu dilakukan pencarian sumber bahan baku yang memiliki kandungan pektin, diantaranya adalah kulit pisang. Pektin dalam kulit pisang dapat diekstrak menggunakan pelarut asam. Penelitian ini bertujuan untuk mengetahui pengaruh volume asam yang ditambahkan pada serbuk kulit pisang raja nangka dengan rasio 1:40, 1:50, dan 1:60. Pelarut asam yang digunakan adalah asam sitrat $7 \%$ dengan suhu estraksi $90{ }^{\circ} \mathrm{C}$ dan lama waktu ekstraksi 120 menit. Pektin yang telah diekstrak dari kulit buah pisang ini berbentuk serbuk, berwarna kecoklatan, dan tidak berbau. Hasil penelitian menunjukkan bahwa rasio bahan/pelarut adalah 1:50 dengan hasil rendemen, berat ekivalen, kadar metoksil, kadar galakturonat, dan derajat esterifikasi berturut-turut adalah 10,68\%, $958 \mathrm{mg}, 3,54 \%, 196 \%$ dan $14,84 \%$. Analisis dengan FTIR menunjukkan bahwa bilangan gelombang yang muncul pada pektin dari kulit pisang ini memiliki karakteristik yang sama dengan pektin komersial.
\end{abstract}

Kata kunci: ekstraksi pektin, volume asam sitrat, rasio bahan dan pelarut

\begin{abstract}
The need for pectin in Indonesia is inscreasing every year. Indonesia relies on pectin import to fulfill domestic pectin needs. So it is necessary to search for sources of raw materials that contain pectin, one of which is banana peel waste. Pectin in banana peels can be extracted using acid solvents. This study aims to determine the effect of the ratio of banana peel powder and solvents $(1: 40,1: 50$, and 1:60) to the yield and quality of pectin extracted. The acid solvent used was $5 \%$ citric acid, and the extraction was conditioned at $90{ }^{\circ} \mathrm{C}$ for 120 minutes. Pectin which has been extracted from banana peels is in powdered form, brownish, and odorless. The results showed that the optimum solvent/solid ratio was 1:50 with a quantity of yield, equivalent weight, methoxyl content, galacturonic acid content, and esterification degree were 10,68\%, $958 \mathrm{mg}, 3,54 \%$, 196\% and $14,84 \%$ respecively. FTIR analysis indicated that pectin from banana peels extract had characteristic near to comercial pectin.
\end{abstract}

Keyword: pectin extraction, ratio peel powder and solvents, citric acid volume

\section{PENDAHULUAN}

Pektin merupakan senyawa hidrokoloid yang umum digunakan dalam industri makanan dan minuman. Pektin mampu membentuk koloid dan gel dalam larutan sehingga dapat digunakan sebagai penstabil dalam industri farmasi dan makanan. Food and Drug Administration (FDA) menggolongkan pektin dan modifikasi pektin kedalam golongan food additive (Cahyanto, 2017; Puspitasari, 2017).

Kebutuhan pektin di Indonesia cenderung mengalami peningkatan di setiap tahun. Indonesia lebih mengandalkan pektin impor untuk memenuhi kebutuhan pektin dalam negeri (Meilina, 2003). Berdasar Statistik Impor
Indonesia (2010) dalam Rohmah (2016), impor pektin nasional pada tahun 2009 sebesar 675.092,21 kg/tahun. Menurut Puspitasari (2017) kebutuhan pektin pada tahun 2020 diperkirakan sebesar 1.320,01 ton/tahun. Oleh karena itu perlu dilakukan pencarian sumber bahan baku yang memiliki kandungan pektin. Sumber bahan baku dapat diperoleh dari limbah makanan yang tidak bernilai ekonomi sehingga mampu meningkatkan nilai tambahnya, diantaranya adalah memanfaatkan kulit pisang. Hal ini disebabkan karena komoditas buah unggulan di Indonesia adalah pisang.

Pektin dalam kulit pisang dapat diekstrak menggunakan pelarut asam anorganik $(\mathrm{HCl}$, $\left.\mathrm{H}_{2} \mathrm{SO}_{4}, \mathrm{HNO}_{3}\right)$ ataupun asam organik $\left(\mathrm{C}_{6} \mathrm{H}_{8} \mathrm{O}_{7}\right.$, 
$\left.\mathrm{CH}_{3} \mathrm{COOH}\right)$. Pelarut asam mampu melepaskan pektin yang terdapat dalam dinding sel tanaman dengan cara memutus ikatan antara protopektin dan material -material yang terdapat dalamtanaman (Gazala dkk., 2017).Chan dan Choo (2013) melakukan ekstraksi pektin dari kulit buahcoklat dengan membandingkan jenis pelarut yang digunakan, yaitu asam sitrat dan HCl. Dari hasil penelitian tersebut diketahui bahwa rendemen pektin tertinggi $(7,62 \%)$ diperoleh saat ekstraksi menggunakanasam sitrat pada suhu $95^{\circ} \mathrm{C}$ selama 3 jam.Gazala dkk. (2017) menyatakan bahwa pektin dapat diekstraksi dari residu padat limbah pengolahan jus apel menggunakan $\mathrm{HCl}, \mathrm{H}_{2} \mathrm{SO}_{4}$, dan asam sitrat. Rendemen pektin terbaik diperoleh saat ekstraksi menggunakan asam sitrat. Madjaga, dkk. (2017) menyatakan bahwa asam sitrat dengan konsentrasi $7 \%$ pada suhu $90-95^{\circ} \mathrm{C}$ menghasilkan rendemen pektin sebesar 39,58\%. Oleh karena itu, pelarut yang digunakan dalam penelitian ini adalah asam sitrat $7 \%$.

Penelitian sebelumnya telah banyak mempelajari tentang pengaruh parameter parameter yang dapat mempengaruhi hasil ekstraksi, diantaranya adalah pengaruh $\mathrm{pH}$, suhu, dan waktu ekstraksi. Kanmani dkk., (2014) melakukan ekstraksi pektin dari kulit jeruk dan diperoleh rendemen yang optimum (36,71 \%) saat ekstraksi menggunakan pelarut asam sitrat pH 3,2 dan suhu $60^{\circ} \mathrm{C}$. Methacanon dkk., (2014) melakukan ekstraksi pektin dari kulit jeruk bali dan diperoleh rendemen yang optimal saat ekstraksi menggunakan asam nitrat $\mathrm{pH} 2$, suhu $90{ }^{\circ} \mathrm{C}$ selama 90 menit. Chahrbaghi dkk., (2017) melakukan ekstraksi pektin dari kulit pistachio dan diperoleh rendemen pektin tertinggi saat proses ekstraksi dilakukan pada suhu $90{ }^{\circ} \mathrm{C}$ dan lama waktu ekstraksi 30 menit.

Berdasarkan latar belakang yang telah diuraikan di atas, masih sedikit yang mempelajari tentang pengaruh rasio bahan dan pelarut terhadap pektin pada kulit pisang. Tujuan dari penelitian ini adalah untuk melakukan optimasi rasio bahan dan pelarut terhadap pektin dari kulit pisang. Produk pektin yang dihasilkan kemudian diuji sifat kimia pektin berdasar syarat mutu serta spesifikasi dalam Farmakope.

\section{MATERI DAN METODE}

\section{Bahan}

Etanol 96\% (Fulltime), asam sitrat monohidrat (Merck), phenolphtalein, $\mathrm{NaOH}$ (Merck), akuades, $\mathrm{NaCl}$, indikator $\mathrm{PP}$, serbuk kulit pisang yang digunakan adalah jenis pisang raja nangka. Kulit pisang dikeringkan pada suhu $50{ }^{\circ} \mathrm{C}$ dalam oven hingga berat konstan. Serbuk kering yang berwarna coklat tersebut lalu diayak dengan ayakan 100 mesh.

\section{Alat}

Peralatan yang digunakan dalam penelitian ini adalah hot plate stirrer, termometer, peralatan gelas analitis, oven, dan spektrofotometer FTIR.

\section{Cara Kerja \\ Ekstraksi Pektin}

Proses ekstraksi pektin dengan metode pemanasan dibagi menjadi empat tahap. Proses ekstraksi ini sesuai dengan prosedur yang pernah dilakukan oleh Maulana, (2015) dan Wathoni dkk. (2019) dengan sedikit modifikasi. Tahap pertama adalah mencampurkan serbuk kulit pisang dan larutan asam sitrat $7 \%$. Rasio serbuk kulit pisang dan asam sitrat yang digunakan adalah 1:40, 1:50, dan 1:60. Tahap kedua adalah pemanasan campuran tersebut pada suhu $90^{\circ} \mathrm{C}$ selama 120 menit.

Tahap ketiga adalah campuran hasil ekstraksi tersebut kemudian disaring menggunakan kain serkai lalu filtrat yang diperoleh didinginkan pada suhu ruang. Tahap keempat merupakan tahap pengendapan pektin. Dalam tahap ini, etanol 95\% ditambahkan dengan perbandingan 1:1 ke dalam filtrat untuk mengendapkan pektin, lalu endapan yang diperoleh dicuci menggunakan etanol 96\% hingga pektin bebas asam yang ditandai filtrat yang diperoleh berwarna bening. Setelah itu, endapan dikeringkan selama 8 jam dalam oven pada suhu $40{ }^{\circ} \mathrm{C}$. Ekstrak kering yang dihasilkankemudian dianalisis menggunakan spektrofotometer Fourier Transform Infra Red (FTIR) dan dihitung persen rendemen serta sifat kimianya, yang meliputi nilai berat ekivalen, kadar metoksil, kadar galakturonat, dan derajat esterifikasi.

\section{Penentuan Sifat Kimia Pektin}

Penentuan sifat kimia ini sesuai dengan penelitian yang telah dilakukan oleh Wathoni dkk. (2019). Penentuan sifat kimia ini diawali dengan cara menentukan berat ekivalen yang dilakukan dengan cara menimbang 0,1 gram serbuk kering lalu ditambahkan $1 \mathrm{~mL}$ etanol 96\% dan $20 \mathrm{~mL}$ akuades bebas $\mathrm{CO}_{2}$. Campuran tersebut kemudian diaduk selama 1 jam hingga tidak ada gumpalan yang tersisa di sisi erlenmenyer lalu ditambah 0,2 gram $\mathrm{NaCl}$ dan 3 
tetes indikator phenolphtalein (PP). Setelah itu, secara perlahan dititrasi menggunakan $\mathrm{NaOH} 0,1$ $\mathrm{N}$ hingga mencapai titik akhir (merah muda) atau hingga larutan mencapai $\mathrm{pH}$ 7,5selama 30 detik. Volume titran dicatat dan digunakan untuk menghitung berat ekivalen (persamaan 1). Larutan netral yang diperoleh ditambah $10 \mathrm{~mL}$ $\mathrm{NaOH} 0,25 \mathrm{~N}$, diaduk 1 jam pada suhu ruang dalam erlenmenyer tertutup. Setelah itu, ditambah $\mathrm{HCl} 0,25 \mathrm{~N}$ sebanyak $10 \mathrm{~mL}$ dan dititrasi dengan $\mathrm{NaOH} 0,1 \mathrm{~N}$ hingga mencapai Titik Akhir Titrasi. Volume titran yang diperoleh digunakan untuk menentukan kadar metoksil (persamaan 2). Kadar galakturonat dihitung dari nilai berat ekivalen dan kadar metoksil (persamaan 3).

$$
\begin{aligned}
& \text { Berat ekivalen }=\frac{\text { berat sampel }(\mathrm{g}) \times 1000}{\text { vol titran }(\mathrm{mL}) \times \mathrm{N} \text { titran }} \\
& \text { Kadar metoksil }(\%)=\frac{\mathrm{mL} \text { titran } \times \mathrm{N} \text { titran } \times 31}{\text { massa sampel }(\mathrm{mg})} \\
& \text { Galakturonat(\%) }=\frac{\mathrm{z} \times 176 \times 100}{\text { massa sampel(mg) }}
\end{aligned}
$$

\section{Keterangan:}

Angka 176 adalah berat terendah ekivalen dari asam pektat dan $\mathrm{z}=$ miliekivalen $(\mathrm{BE}+$ metoksil).

$$
\mathrm{D} E(\%)=\frac{176 \times \% \text { metoksil } \times 100}{31 \times \text { kadar galakturonat }}
$$

Keterangan:

$\mathrm{DE}=$ Derajat Esterifikasi

Nilai 31 merupakan berat molekul dari gugus metoksil.

\section{HASIL DAN PEMBAHASAN}

Buah pisang yang dipilih adalah buah pisang yang tidak terlalu matang karena jika terlalu matang pektin yang terdapat di dalam kulit pisang telah berubah menjadi asam pektat.

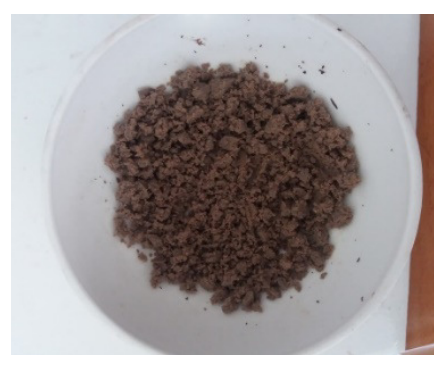

Gambar 2. Serbuk hasil ekstraksi kulit pisang
Asam sitrat digunakan sebagai pelarut untuk mengekstraksi pektin dari kulit pisang. Asam sitrat tergolong asam organik yang dapat meminimalisir terdegradasinya molekul pektin menjadi asam pektat. Farmakope Indonesia V (2014) menyatakan bahwa pektin berbentuk serbuk, berwarna putih kekuningan, dan hampir tidak berbau sedangkan dalam penelitian ini menghasilkan pektin yang berbentuk serbuk, berwarna coklat, dan tidak berbau (Gambar 2). Menurut Maulana (2015), pektin yang berwarna coklat ini disebabkan karena bahan baku yang kulit pisang yang digunakan telah mengalami oksidasi saat penyimpanan. Proses penyimpanan pektin pada penelitian ini diletakkan di dalam botol bening sehingga mudah terkena sinar matahari.

Serbuk kering hasil ekstraksi lalu diuji kualitatif menggunakan etanol, $\mathrm{NaOH}$, dan $\mathrm{HCl}$. Berdasar hasil tersebut, serbuk kering yang diperoleh positif pektin karena ketika serbuk kering tersebut dilarutkan menggunakan akuades dan ditambah dengan etanol dapat mengendap. Selain itu, saat serbuk kering dilarutkan dengan air dan ditambah dengan larutan $\mathrm{NaOH} 2 \mathrm{~N}$ dapat membentuk gel, serta ketika dilanjutkan dengan penambahan larutan $\mathrm{HCl} 3 \mathrm{~N}$ dan dididihkan dapat menggumpal.

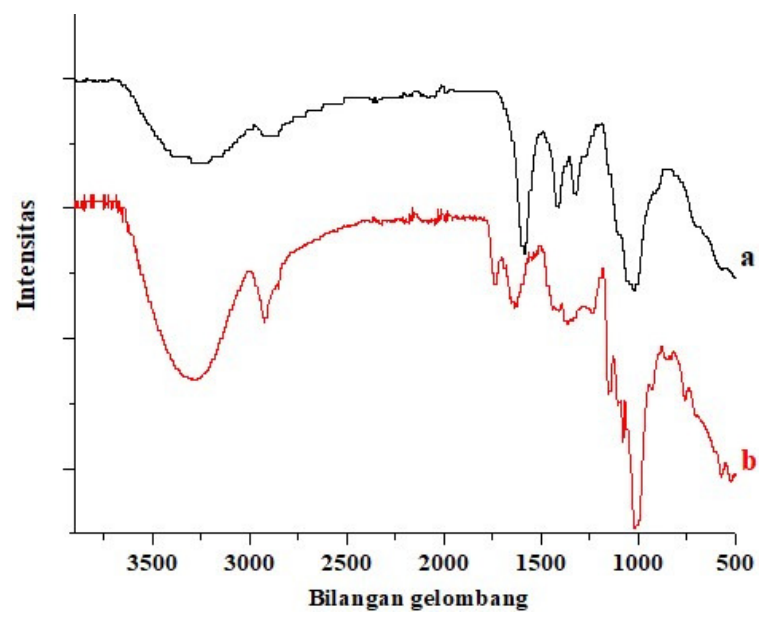

Gambar 3. Spektra FTIR pektin komersial (a) dan pektin hasil ekstraksi kulit pisang (b)

Gugus fungsional pektin dari kulit pisang ini kemudian dianalisis menggunakan FTIR (Gambar 3). Puncak utama gugus hidroksil pada pektin dan pektin komersial menunjukkan puncak yang khas yaitu puncak yang lebar dan masing - masing berada pada bilangan gelombang 3402 dan $3367 \mathrm{~cm}^{-1}$. Gugus alifatik $\mathrm{C}-\mathrm{H}$ ulur dan gugus karbonil $\mathrm{C}=\mathrm{O}$ ulur ester 
muncul di bilangan gelombang 2927 dan 1747 $\mathrm{cm}^{-1}$ untuk pektin, serta 2939 dan $1639 \mathrm{~cm}^{-1}$ untuk pektin komersial. Puncak $1442 \mathrm{~cm}^{-1}$ menunjukkan adanya gugus metil $\mathrm{CH}$ pada spektra pektin dan pektin komersial. Selain itu, munculnya bilang gelombang pada 1161 dan $1153 \mathrm{~cm}^{-1}$ mengindikasikan adanya ikatan $\mathrm{C}-\mathrm{O}$ dalam alkohol, ester, dan asam karboksilat. Berdasar spektra FTIR tersebut, pektin yang telah ter-ekstrak dan standar pektin memiliki spektra yang serupa. Hasil spektra FTIR pektin yang dihasilkan dalam penelitian ini juga serupa dengan hasil spektra FTIR pektin yang dihasilkan dalam penelitian Faravash dan Ashtian, (2008); Yang, dkk. (2018); Wathoni dkk.(2019);

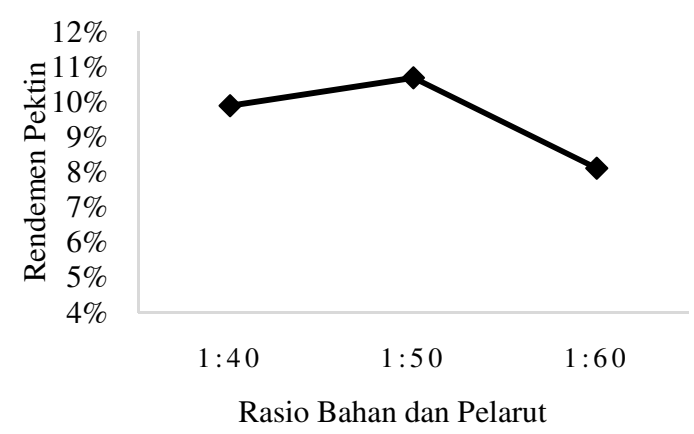

Gambar 4. Rasio bahan dan pelarut terhadap rendemen pektin

Gambar 4 menunjukkan hasil dari rasio bahan dan pelarut terhadap rendemen pektin. Semakin banyak volume asam yang ditambahkan, maka semakin banyak pelarut yang mampu melarutkan pektin yang terdapat di dalam serbuk kulit pisang tersebut sehingga rendemen pektin semakin meningkat. Akan tetapi, ketika volume pelarut semakin ditingkatkan, rendemen yang dihasilkan menurun karena adanya perubahan $\mathrm{pH}$ pada tahap pengendapan pektin terjadi. $\mathrm{pH}$ pada tahap ini disebut precipitation-pH (P-pH). Volume asam mempengaruhi $\mathrm{pH}$ akhir ekstraksi, oleh karena itu jika volume asam terlalu banyak maka P-pH menurun. Apabila P-pH tidak berada dalam range yang sesuai untuk terjadi pengendapan pektin, maka mengakibatkan rendemen pektin menurun (Faravash dan Ashtiani, 2008; Guo dkk., 2016). Volume asam berbanding lurus dengan banyaknya pektin yang berhasil terekstrak dari kulit pisang. Akan tetapi pada volume asam tertentu, pektin dapat terdegradasi menjadi asam pektat, sehingga rasio bahan dan pelarut ini penting untuk dilakukan. Volume asam berbanding lurus dengan banyaknya pektin yang berhasil ter-ekstrak dari kulit pisang. Akan tetapi pada volume asam tertentu, pektin dapat terdegradasi menjadi asam pektat, sehingga rasio bahan dan pelarut ini penting untuk dilakukan.

Kualitas pektin dapat diketahui berdasarkan karakteristik kimia yang dihitung berdasar nilai berat ekivalen, kadar metoksil, asam galakturonat, dan derajat esterifikasi. Hasil karakterisasi sifat kimia pektin dapat dilihat dalam Tabel 1. Berat ekivalen pektin dari limbah kulit pisang dengan rasio bahan dan pelarut 1:40, 1:50, dan 1:60 secara berturut - turut adalah 871, 958, dan 901. Azad dkk. (2014) menyatakan bahwa faktor yang mempengaruhi nilai berat ekivalen diantaranya adalah tingkat kematangan buah. Pektin yang diekstrak dari buah yang terlalu matang (over ripens) menghasilkan berat ekivalen lebih rendah dibandingkan dengan pektin yang diekstaksi dari buah yang matang (mature). Nilai berat ekivalen ini juga bergantung dengan jumlah asam bebas yang terdapat dalam pektin.

Tabel 1. Kualitas pektin kulit pisang

\begin{tabular}{cccc}
\hline \multirow{2}{*}{ Parameter } & \multicolumn{3}{c}{ Rasio bahan dan pelarut } \\
\cline { 2 - 4 } $\mathbf{1 : 4 0}$ & $\mathbf{1 : 5 0}$ & $\mathbf{1 : 6 0}$ \\
\hline Berat Ekivalen & 871 & 958 & 901 \\
\hline $\begin{array}{c}\text { Kadar Metoksil } \\
(\%)\end{array}$ & 2,59 & 3,54 & 2,40 \\
\hline $\begin{array}{c}\text { Kadar } \\
\text { Galakturonat (\%) }\end{array}$ & 140 & 196 & 174 \\
\hline $\begin{array}{c}\text { Derajat } \\
\text { Esterifikasi (\%) }\end{array}$ & 10,31 & 14,84 & 13,51 \\
\hline
\end{tabular}

Kadar metoksil dan asam galakturonat dapat mempengaruhi struktur dan tekstur gel pektin yang terbentuk. Hasil yang diperoleh ini menunjukkan bahwa pektin limbah kulit pisang merupakan pektin metoksil rendah. Berdasar Farmakope Indonesia edisi V, pektin dikatakan termasuk kadar metoksil rendah jika memiliki nilai kadar metoksil $<6,7 \%$ dan memiliki nilai $\%$ Derajat Esterifikasi $<50 \%$. Pektin metoksil rendah dapat membentuk gel dengan penambahan sedikit gula atau tanpa gula dalam kation divalen. Pektin metoksil rendah mampu membentuk gel atau mengendap dengan adanya ion kalsium (Wathoni dkk., 2019).

Kadar galakturonat yang diperoleh dalam penelitian ini tergolong tinggi, yaitu $140 \%$, $196 \%$, dan $174 \%$ masing - masing pada pektin dengan rasio bahan dan pelarut 1:40, 1:50, dan 1:60. Kadar galakturonat pada pektin kulit pisang ini masih belum sesuai dengan range yang 
ditentukan oleh Farmakope Indonesia edisi V dan Handbook of Pharmaceutical Excipient (HPE), dimana kadar asam galakturonat dengan kualitas yang baik adalah sebesar $<74 \%$. Kadar galakturonat yang cukup tinggi ini dapat disebabkan karena masih adanya gula dalam endapan pektin (Shaha dkk., 2013). Kadar galakturonat yang lebih dari $100 \%$ ini menunjukkan bahwa masih adanya kandungan air di dalamnya sehingga mempengaruhi hasil analisis.

\section{SIMPULAN}

Rasio bahan dan pelarut dapat mempengaruhi rendemen pektin yang telah diekstraksi dari kulit pisang raja nangka. Hasil rendemen pektin yang diperoleh pada saat proses ekstraksi dengan rasio bahan/pelarut 1:40, 1:50 dan 1:60 adalah $9,88 \%, 10,68 \%$ dan $8,10 \%$. Pektin yang dihasilkan dalam penelitian ini digolongkan dalam pektin bermetoksil rendah karena memiliki nilai metoksil $<6,7 \%$ dan $\% \mathrm{DE}$ $<50 \%$. Kadar galakturonat dalam pektin dari kulit pisang ini masih tergolong tinggi, hal ini disebabkan karena masih adanya kandungan gula yang terdapat dalam endapan pektin sehingga pektin yang diperoleh belum murni.

\section{DAFTAR PUSTAKA}

Anonim, 2014. Farmakope Indonesia. edisi V. Jakarta: Departemen Kesehatan Republik Indonesia.

Azad, A.K.M., Ali, M.A., Akter, Mst. Sorifa, Rahman Md. Jiaur, Ahmed M. 2014. Isolation and Characterization of Pectin Extracted from Lemon Pomace during Ripening. Journal of Food and Nutrition Sciences. 2(2):30-35.

Cahyanto HA. Pektin Jeruk Bali (Citrus Maxima, L) dalam Formulasi Sirup Kering Buah Mengkudu. Jurnal Riset Teknologi Industri. 2017. 11(1):43 - 49.

Chaharbaghi, E., Khodaiyan, F., Hosseini, S.S. 2017. Optimization of Pectin from Pistachio Green Hull as a New Source. Carbohydrate Polymers. 173: 107-113.

Chan, S.-Y dan Choo, W.-S. 2013. Effect of Extraction Conditions on the Yield and Chemical Properties of Pectin from Cocoa Husks. Food Chemistry. 141:3752-3758.

Dirjen Bina Kefarmasian dan Alat Kesehatan. 2014. Farmakope Indonesia, V. Menteri Kesehatan, Republik Indonesia, Jakarta.
Faravash, R.S., Ashtian, F.Z. 2008. The Influence of Acid Volume, Ethanol-ToExtract Ratio and Acid Washing Time on the Yield of Pectic Substances Extraction from Peach Pomace. Food Hydrocolloids. 22: 196-202.

Febriyanti, Y., Razak, A.R., Sumarini, N.K. 2018. Ekstraksi dan Karakterisasi Pektin dari Kulit Buah Kluwih (Artocarpus camansi Blanco). Kovalen. 4(1): 60-73.

Fitria, V. 2013. Karakterisasi Pektin Hasil Ekstraksi dari Limbah Kulit Pisang Kepok (Musa balbisiana ABB). Skripsi. Program Studi Farmasi. Fakultas Kedokteran dan Ilmu Kesehatan. UIN Syarif Hidayatullah Jakarta.

Gazala, K., Masoodi, F.A., Masarat, H.D., Rayees, B., dan Shoib, M.W. 2017. Extraction and Characterization of Pectin from Two Apple Juice Concentrate Processing Plants. International Food Research Journal. 24(2):594-599.

Guo, X., Meng, H., Tang, Q., Pan, R., Zhu, S., dan Yu, S. 2016. Effects of the Precipitation $\mathrm{pH}$ on the Ethanolic Precipitation of Sugar Beet Pectins. Food Hydrocolloids. 52: 431-437.

Kanmani, P., Dhivya, E., Aravind, J., Kumaresan, K. 2014. Extraction and Analysis of Pectin from Citrus Peels: Augmenting the Yield from Citrus limon using Stastical Experimental Design. Iranica Journal of Energy \& Environment. 5(3): 303-312.

Madjaga, B.H., Nurhaeni, Ruslan. 2017. Optimalisasi Pektin dari Kulit Buah Sukun (Artocarpus altilis). Kovalen. 3(2):158165.

Maulana, S. 2015. Ekstraksi dan Karakterisasi Pektin dari Limbah Kulit Pisang Uli (Musa paradisiaca L. ABB). Skripsi. Program Studi Farmasi. Fakultas Kedokteran dan Ilmu Kesehatan. Universitas Islam Negeri Syarif Hidayatullah Jakarta.

Meilina, H.,Sailah, I. 2003. Produksi Pektin dari Kulit Jeruk Lemon (Citrus medica). Prosiding Simposium Nasional Polimer V (pp. 117 - 126). ISSN 1410-8720.

Methacanon, P., Krongsin, J., Gamonpilas, C. 2014. Pomelo (Citrus maxima) pectin: Effects of Extraction Parameters and Its Properties. Food Hydrocolloids. 35: 383391. 
Puspitasari, L.N.,Puspitasari, N. 2017. Prarencana Pabrik Pektin dari Kulit Jeruk Bali Kapasitas 264 ton Pektin/tahun. Thesis. Jurusan Teknik Kimia. Fakultas Teknik. Universitas Katolik Widya Mandala, Surabaya.

Rohmah, Y. 2016. Outlook Komoditas Pertanian Sub Sektor Holtikultura. Kementerian Pertanian: Pusat Data dan Sistem Informasi Pertanian.

Shaha, R.K., Punichelvana, Y.N.A.P., dan Afandi, A. 2013. Optimized Extraction Condition and Characterization of Pectin from Kaffir Lime (Citrus hystrix).
Research Journal of Agriculture and Forestry Sciences. 1(2): 1-11.

Wathoni, N., Shan, C.Y., Shan, W.Y., Rostinawati, T., Indradi, R.B., Pratiwi, R., Muchtaridi, M. 2019. Chararcterization and Antioxidant Activity of Pectin from Indonesian Mangosteen (Garcinia mangostana L.) Rind. Heliyon. 5: 1-5.

Yang, X., Nisar, T., Hou, Y., Gou, X., Sun, L., Guo, Y. 2018. Pomegranate Peel Pectin can be used as an Effective Emulsifier. Food Hydrocolloids. 85: 30-38. 